\title{
Observance of Architectural Principles in Hospital Construction; A Step Towards Energy Consumption Optimization
}

\author{
Zahra Mohseni ${ }^{*}$ \\ 1'Department of Architecture, Isfahan (Khorasgan) Branch, Islamic Azad University, Isfahan, Iran \\ *Corresponding Author: Zahra Mohseni, Department of Architecture, Isfahan (Khorasgan) Branch, Islamic Azad \\ University, Isfahan, Iran. Tel: +98-9130185952, Email: zahra.moh3ni1995@gmail.com
}

Received May 13, 2018; Accepted May 24, 2018; Online Published August 29, 2018

\section{Dear Editor,}

The prevention of energy loss has been considered one of the most significant issues addressed by industrial, developed countries in recent decades. ${ }^{1}$ Improving energy efficiency in the construction sector is a practical, established action taken to reduce greenhouse gas emissions and energy costs. ${ }^{2}$ Simple, practical, accessible, and economical strategies can be used to reduce energy consumption, and optimization solutions can help decrease mechanical system demands and improve quality, thus increasing the efficiency of a building. ${ }^{3}$ Moreover, the utilization of architectural design and urban development methods to save on fuel and energy consumption in buildings is essential at national and international levels. ${ }^{4}$ Architecturally, the design of health centers is more important than that of all other spaces. ${ }^{5}$ Focusing on energy consumption management and control in such spaces is of much importance given their high energy consumption and the large amounts of pollutants they generate. As the building designer, the architect can affect, to a great extent, optimum energy consumption and energy loss reduction.

The first factor that must be considered is the use of passive methods to reduce energy consumption; in other words, the use of passive architectural design for a building. These methods are addressed in the predesign phase of architecture and include the accurate and proper identification of climatic profiles of the area and, consequently, the use of environmentally-friendly architectural designs; building geometry or volume, particularly the architectural plan organization; and building orientation relative to the geographic north. These factors can play a significant role in reducing energy consumption. For example, solar and wind energies can be absorbed and preserved for heating and cooling purposes using passive architectural design system, such that the
\end{abstract}

need for auxiliary facilities is minimized.

In the design phase, exploiting creative solutions in constructing hospitals in line with static performance is an important step that can be taken toward reducing and controlling energy consumption. At this stage, special attention must be given to sustainable architecture as a subset of sustainable design. The purpose of such design is to minimize energy resources consumption while simultaneously reducing environmental damages. It is highly important that the construction of hospitals be based on principles such as intelligent building design, green hospital, and thermal insulation and on modeling programs of building energy, energy management, and energy audit.

Thus, given the effect of hospital architecture design on energy consumption and costs, and given the lack of studies conducted in this regard, it is suggested that academic communities and health and engineering policymakers take a more serious look at this problem. Conducting interventional studies, investigating the effect of using different methods on reducing energy consumption, and choosing economical practices are necessary.

\section{Conflict of Interest Disclosures}

The author declares that there is no conflict of interest.

\section{Ethical Approval}

Not applicable.

\section{References}

1. Zhou L, Haghighat F. Optimization of ventilation systems in office environment, Part II: Results and discussions. Build Environ. 2009;44(4):657-665. doi:10.1016/j. buildenv.2008.05.010.

2. Hastings SR. Breaking the "heating barrier": Learning from the first houses without conventional heating. Energy Build.

Copyright $($ C 2018 The Author(s). This is an open-access article distributed under the terms of the Creative Commons Attribution License (http:// creativecommons.org/licenses/by/4.0), which permits unrestricted use, distribution, and reproduction in any medium, provided the original work is properly cited. 
2004;36(4):373-80. doi:10.1016/j.enbuild.2004.01.027.

3. Khodakarami J, Ghobadi P. Optimizing of energy consumption in an office building equipped with intelligent management system. Energy Engineering \& Management. 2016;6(2):12-23. [Persian].

4. Fazeli A, Heidari S. Energy efficiency in residential areas of
Tehran using Rotterdam Energy Approach Planning (REAP) Quarterly Journal of Energy Policy and Planning Research. 2013;1(3):83-96. [Persian].

5. Sodagar S, Mafakher F. Analysis of the necessity of hospital design green approach to sustainable architecture. Urban Management. 2016;45:517-532. [Persian]. 